\title{
A Escolha Profissional no Direcionamento da Carreira dos Universitários
}

The Professional Choice In Directing The Career

La Elección Profesional En La Orientación

De La Carrera De Los Universitarios
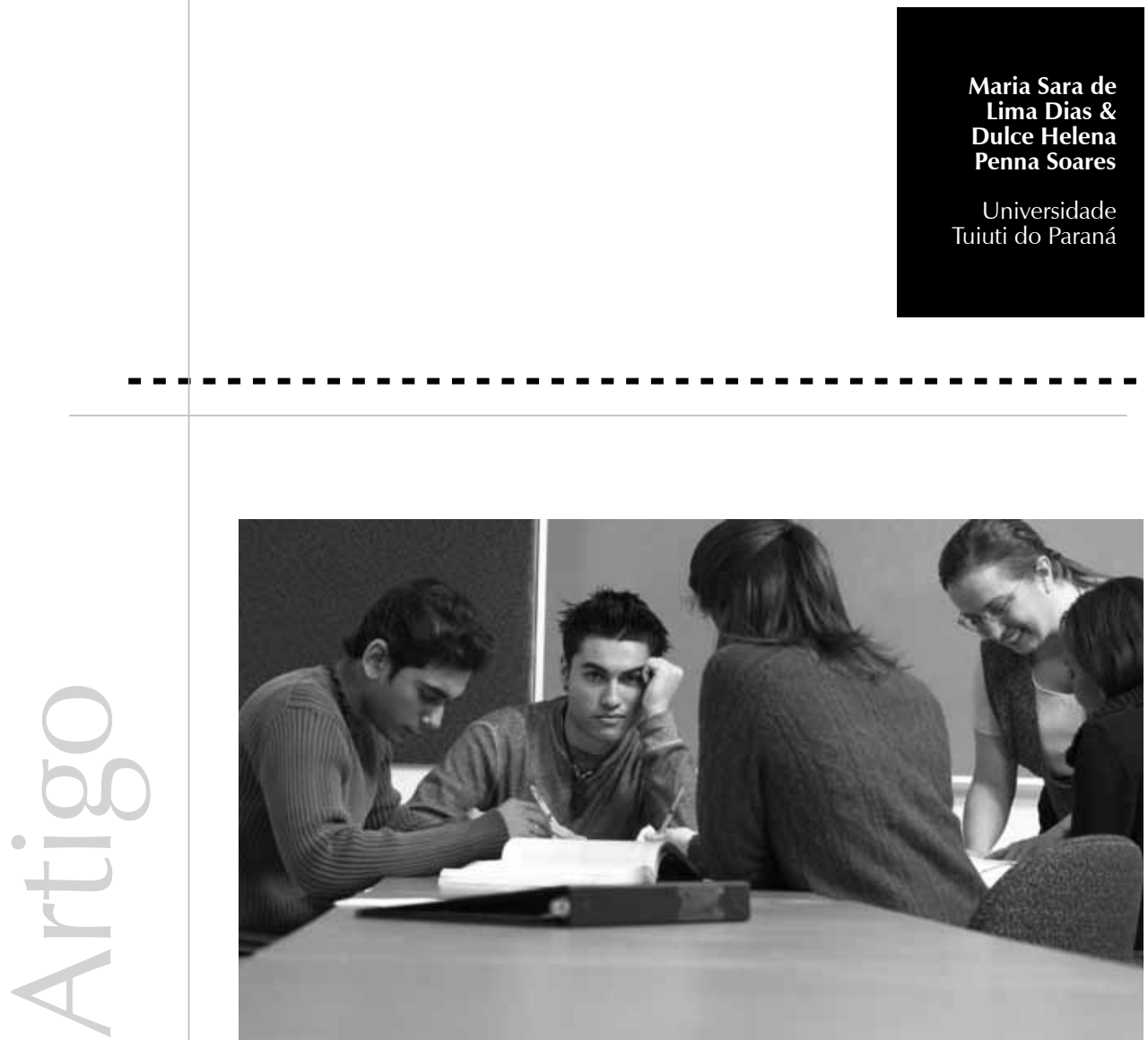
Resumo: Objetivou-se, neste trabalho, analisar a escolha profissional em sua relação com o direcionamento da carreira de universitários. Foram utilizadas a base teórica de Vygotsky e uma metodologia qualitativa com entrevistas semiestruturadas submetidas à análise do discurso. Foram entrevistados quatorze formandos e se apresentam para a finalidade deste artigo quatro entrevistas, que ilustram o conjunto dos formandos. No processo de análise, observou-se a emergência das seguintes categorias: escolhendo sem saber, o diploma considerado mais importante do que o trabalho e o medo do mercado. As carreiras para os universitários se traduzem em ambiguidades, satisfação e insatisfações com o curso escolhido. Na medida em que iniciam sua vida profissional, a busca desse grupo de jovens é por um emprego bem remunerado e estável, não importando a atividade a ser desenvolvida. Os jovens revelam sentimentos frequentes de insegurança, indecisões e mesmo indiferença frente às suas trajetórias profissionais futuras e escolhem profissões e carreiras tendo como pano de fundo um contexto extremamente competitivo e excludente do mercado de trabalho; assim, considera-se a orientação na universidade um aspecto fundamental para auxiliar no processo de transição para o mercado de trabalho.

Palavras-chave: Estudantes universitários. Escolha profissional. Aspirações profissionais. Mercado de trabalho.

Abstract: This work aims to analyse the professional choice in its relation with the college studies career directions. Vygotsky's theoretical basis and qualitative methodology with semi-structured interviews submitted to speech analysis were used. Fourteen students were interviewed and four, who represent the group of students, had their interviews used for this article purpose. In the analysis of the process it was observed the emergency of the following categories: choosing without knowledge, the diploma considered more important than the work and the fear of the job market. The careers for the college students are ambiguously defined: satisfaction and dissatisfaction with the chosen course. In so far as they start their professional life the search of the group is to find a well paid and stable job position without minding the activity to be developed. As they start facing their professional trajectories feelings such as insecurity, indecision and indifference are frequently revealed. Young people choose jobs and careers having as background an extremely competitive and excluding job market. Therefore, the orientation at the university is a meaningful aspect to assist them in the transition process to the job market.

Keywords: College students. Occupational aspirations. Career. Labor market.

Resumen: En este trabajo se ha objetivado analizar la elección profesional en su relación con la orientación de la carrera de los universitarios. Se han utilizado la base teórica de Vygotsky y una metodología cualitativa con entrevistas semiestructuradas sometidas al análisis del discurso. Han sido entrevistados catorce universitarios que se estaban graduando y se presentan para la finalidad de este artículo cuatro entrevistas que ilustran el conjunto de esos graduandos. En el proceso de análisis, se ha observado la emergencia de las categorías descriptas a continuación: eligiendo sin saber, el diploma considerado más importante que el trabajo y el miedo del mercado. Las carreras para los universitarios se traducen en ambigüedades, satisfacción e insatisfacciones con la carrera elegida. A medida que comienzan su vida profesional, la búsqueda de ese grupo de jóvenes es de un trabajo bien remunerado y estable, sin importar la actividad a desarrollarse. Los jóvenes revelan sentimientos frecuentes de inseguridad, indecisiones e incluso indiferencia ante sus trayectorias profesionales futuras y eligen profesiones y carreras que tienen como característica un contexto extremadamente competitivo y excluyente del mercado de trabajo. De esa manera, se considera la orientación en la universidad un aspecto fundamental para servir de auxilio en el proceso de transición para el mercado de trabajo.

Palabras clave: Estudiantes universitarios. Elección Profesional. Aspiraciones profesionales. Mercado de trabajo.

\section{A dimensão da escolha: a carreira}

\begin{abstract}
A dimensão da escolha do curso superior deve ser considerada sob a perspectiva de continuidade da carreira. Muitos fatores indicam possibilidade de risco ao se pensar sobre o futuro profissional. O formando está vivenciando um tempo histórico em que o processo de transição ganha
\end{abstract}

contornos diferenciados com o aumento do número de cursos superiores, as estatísticas veiculadas na mídia sobre o desemprego e o alargamento do tempo de permanência na universidade, entre outros fatores, conforme corroboram Fonseca e Azevedo (2007) e Pochmann (2007). 
O fato de ser

um formando posiciona

o sujeito na

convergência

entre o sistema educativo

e o sistema

produtivo, no

paradigma da

qualificação

para o trabalho

(Pochmann,

1998, 2007;

Antunes, 2006:

Teixeira \& Gomes,

2004).
O fato de ser um formando posiciona o sujeito na convergência entre o sistema educativo e o sistema produtivo, no paradigma da qualificação para o trabalho (Pochmann, 1998, 2007; Antunes, 2006; Teixeira \& Gomes, 2004). O contexto dita normas de preparação para o ingresso no mundo do trabalho, porém as noções de carreira dentro da profissão escolhida ainda não permitem ao jovem constituir os direcionamentos ou os contornos de uma expectativa futura.

Sobre o tema da escolha profissional existente no Brasil, encontram-se trabalhos com distintas abordagens e orientações teóricometodológicas. Historicamente, a orientação profissional (OP) tem servido mais a alunos oriundos da escola particular, que têm maiores possibilidades de escolha (Sparta, 2003; Soares \& Lisboa, 2000) que os da escola pública. Ainda existe na área da OP a necessidade de desenvolver pesquisas sobre $o$ processo da escolha profissional na transição.

Se a condição de classe interfere nas trajetórias profissionais, é importante relativizar a expressão escolha (Borges-Andrade \& Bastos, 2004), visto que os jovens, dentro de uma sociedade capitalista, têm graus limitados de liberdade de escolher. Jonhson (2000) trabalha a questão da escolha como fenômeno e a OP como processo de assistência que nem sempre é eficaz. Os estudos de Ferreti (1988a, 1988b) e Bock (1995) fundamentam a compreensão da escolha profissional como campo de estudo, que se compreende não poder ser limitado ao ingresso no contexto universitário.

Bardagi, Lassance, Paradiso e Menezes (2006) investigaram a satisfação com a escolha profissional e as expectativas quanto à entrada no mundo do trabalho. Seus resultados demonstram a insegurança dos alunos quanto ao início da atividade profissional e a necessidade de intervenções específicas para o público universitário. Vieira e Coimbra (2006) apresentam um estudo exploratório efetuado com finalistas do ensino superior em Portugal e afirmam que o sucesso está diretamente relacionado à preparação para o ingresso profissional.

Para a compreensão da carreira, é inevitável abordar Super $(1957,1983)$ e Savickas (2004), que propõem a diferenciação dos serviços de carreira em: aconselhamento de carreira, educação para a carreira, orientação vocacional, terapia ocupacional, colocação ocupacional e treino adaptativo ao posto de trabalho. Sua teoria de carreira propõe um método da abordagem narrativa e biográfica (Savickas, 2004, 2005).

Considera-se fundamental avaliar a situação de transição, com fatores pessoais, recursos e apoios, incluindo o apoio social, e estratégias possíveis ou dominadas pela pessoa. Chanlat (1996) afirma que existem quatro tipos de carreira: a burocrática, a profissional e a socio-política; para ele, carreira significa um ofício, uma profissão que apresenta etapas, uma progressão.

Segundo Dutra (2002), a carreira está ligada às organizações, sendo um trabalho de ajuda aos sujeitos para avaliarem o seu potencial e traduzi-lo em escolhas futuras. Conforme Soares e Lisboa, "é a continuidade da vida do indivíduo no trabalho para produzir algo; pode ser a seqüência do envolvimento deste nas experiências de trabalho ao longo da vida" (2000, p. 36).

A escolha inicial de um curso superior está vinculada a possibilidades e condições do ingresso na universidade. A problemática da escolha se amplia porque, segundo o Censo da Educação Superior (2009), estão registrados 28.671 cursos de graduação e 295 sequenciais de formação específica, mais concentrados em universidades $(49,8 \%$ dos presenciais) do que em faculdades $(35,6 \%)$. O restante está distribuído entre 
centros universitários $(12,9 \%)$ e institutos federais de tecnologia $(1,74 \%)$. A escolha inicial, portanto, limita e direciona futuras decisões de carreira que são muitas vezes desconhecidas no momento do ingresso.

No momento da transição, segundo Sarriera, Rocha e Pizzinato (2004), o jovem tem sempre uma finalidade ou um objetivo, como, por exemplo, ajudar os pais na velhice, ganhar dinheiro e casar, dentre outros desejos. As condições objetivas de vida e de seus familiares interferem na escolha, (Fernandes, 2006; Soares, 2002).

As oscilações do mercado, sejam globais ou locais, provocam múltiplas consequências: deslocamentos de moradia e alterações em padrões e estilos de vida pretendidos ou preteridos. (Vieira \& Coimbra, 2006; Fonseca \& Azevedo, 2007; Antunes, 2006). Esses autores, entre outros, influenciaram a prática da orientação profissional no Brasil no que se refere ao planejamento de carreira. "Ao se inscrever na sociedade como responsável pela própria vida profissional, o jovem busca um trabalho que fundamente sua escolha, garanta sua sobrevivência e traga satisfação pessoal e profissional" (Soares \& Lisboa, 2000, p. 36). Este trabalho objetivou refletir sobre como os formandos interpretam a escolha de carreira frente ao ingresso no mercado de trabalho.

\section{Considerações sobre o método}

Dentro da perspectiva da Psicologia históricocultural, o método baseia-se nas contribuições das teorias de Vygotsky (1991a, 1991b, 2000), em que o sujeito é compreendido como uma síntese aberta, em constante movimento de apropriação de aspectos da realidade.

Com o objetivo de buscar a relação entre a escolha profissional no direcionamento de carreira, foram utilizadas entrevistas semiestruturadas que tiveram a duração de uma hora, realizadas com quatorze formandos, sete homens e sete mulheres, com idades variando entre 22 e 27 anos, de uma universidade federal brasileira. $\mathrm{O}$ único requisito para participar da pesquisa era a disponibilidade para a participação, o que permitiu que universitários que tivessem algum tipo de interesse sobre o tema da carreira pudessem participar.

As entrevistas foram transcritas e submetidas a análises, em que as seguintes categorias se evidenciaram: escolhendo sem saber, o diploma considerado mais importante do que o trabalho e o medo do mercado. Os resultados apresentados neste artigo se referem somente a quatro dos entrevistados, escolhidos porque possibilitam ilustrar e fundamentar as categorias encontradas em todos os outros. Para este artigo, não se toma a totalidade dos formandos e nem a totalidade dos discursos produzidos: apresentam-se os discursos em trechos de seus enunciados, que, de uma forma abrangente, são considerados representantes legítimos do coletivo dos entrevistados.

\section{Resultados e discussão}

Apresenta-se uma pequena história de cada entrevistado, que recebeu um nome fictício a fim de resguardar sua identificação, com elementos que nos permitem adentrar a sua subjetividade. ANA (Serviço Social) tem 22 anos, mora sozinha, escolheu o curso de Psicologia e, como não passou no vestibular em sua cidade natal, cursa Serviço Social. BARA (Sistemas de Informação) tem 23 anos e mora com o marido, queria arquitetura e, por não dispor de condições financeiras, optou por um curso noturno. BIA (Geografia) mora sozinha, tem 22 anos de idade, também queria cursar Psicologia, mas não passou, e a Geografia foi sua opção. BONO (Engenharia Mecânica) tem 22 nos, mora com amigos, queria fazer o curso de 
música ou de esporte, mas, como não "dava dinheiro", optou por Engenharia Mecânica. Os resultados obtidos na pesquisa sugerem as categorias: escolhendo sem saber, o diploma considerado mais importante que o trabalho, o medo do mercado de trabalho e as estratégias de enfrentamento, abaixo descritas.

\section{Escolhendo sem saber}

As escolhas iniciais são tramadas dentro da ausência de informação sobre o curso superior e sobre o mercado de trabalho. ANA: - Quando eu entrei no curso, eu não fazia ideia do que era o serviço social. BIA: - Porque a minha prima fazia, e eu... meio que gostei do nome assim... Ou ainda BARA: - Eu tinha optado por... na verdade... eu não sabia o que eu queria, até o terceiro ano. BONO: - ... Quando eu entrei no curso, eu não fazia ideia do que era. Nessa etapa, a escolha é uma obrigação, e revela-se assim a importância da OP nesse processo, que é realizado sem as informações necessárias, como corroboram os estudos de Sarriera, Rocha e Pizzinato (2004), Fernandes (2006) e Soares (2002). A informação é um aspecto fundamental da escolha profissional.

Quando escolhe, o jovem deve estar preparado para abrir mão de outras tantas carreiras, como foi o caso a seguir: BIA: Porque eu não tinha muita noção do que era, eu só sabia que eu iria trabalhar com pessoas. Uma possibilidade mais próxima ou alcançável é decidir por uma carreira que envolva o trabalho com pessoas, o autoconhecimento; saber o que gosta e o que não gosta também é outro fator fundamental para subsidiar escolhas profissionais coerentes com o projeto de trabalho dos formandos.

A realidade das escolhas é limitada pelas possibilidades econômicas e condicionais dos alunos, ainda mais para aqueles que vêm do interior, como ANA: - Aí eu passei para
Caçador, eu fui para lá e eu queria fazer..., só que foi um pouco caro para mim, sabe, não deu. Eu tinha que morar sozinha e tudo mais. Quando escolhem uma profissão, aspectos da localidade, das condições econômicas dos alunos e das ofertas de oportunidades possíveis devem ser consideradas, assim, falamos sempre de escolhas possíveis.

Passar nos cursos historicamente mais valorizados na universidade consiste em um desafio, como nesta fala: BONO: - ... Eu era música ou esporte, mas não dava para ganhar dinheiro, assim era só isso.... era isso... é o que eu queria. Nem sempre o jovem decide pelo que quer mais, ou deseja, mas, muitas vezes, as escolhas se dão por cursos que são valorizados socialmente. A impossibilidade do acesso ao curso desejado faz com que o sujeito se responsabilize, como neste caso: BARA: - ... Ficou um pouco complicado para mim... por questões pessoais. As questões pessoais não são percebidas como condições sociais; o contexto é deixado de lado na consideração dos jovens sobre suas escolhas.

Condições materiais promovem elementos limitadores da escolha, como no caso de BARA: - ... Eu não estava muito segura se era aquilo que eu queria fazer, ...eu comecei a avaliar o mercado de trabalho, avaliar a questão financeira, porque o meu pai... não tem muitas condições né? (...) BARA afirmou que não estava muito segura de sua escolha, mas que tinha o dever de escolher, assim, a análise do mercado é outro elemento importante na decisão da carreira.

A escolha emerge no discurso: BARA: Informática é uma coisa útil hoje. A palavra útil engendra o sentido produzido no seio de uma sociedade e cultura. O discurso de BARA ilustra o aspecto da culpabilização do jovem por suas inseguranças no momento da escolha; BARA : - Daí eu pensava: alguma coisa deve estar errada, e deve ser comigo. Dessa forma, ao escolher, supera a insegurança presente 
pelo desconhecimento e pela desinformação do mercado de trabalho.

As consequências de sua ação remetem à divisão social do trabalho, a uma profissão específica e que direciona a carreira futura. BARA: - Daí, dentre os cursos noturnos, eu fui por exclusão. Ao excluir, no início de sua carreira profissional, o que poderia fazer daqueles cursos que não faria, exclui, na verdade, o que não poderia ter feito. $\mathrm{O}$ jovem segue tecendo suas escolhas, mesmo sem saber que estas repercutem ao longo de sua vida acadêmica e sustentam trajetórias profissionais e carreiras futuras, portanto, a escolha inicial tem um valor social como dimensão da carreira.

\section{O diploma mais importante que o trabalho}

Pertencer à classe social dos diplomados é mais importante e tem mais significado do que a escolha profissional em si. Os diplomas retêm seu valor histórico e social simbólico, como no caso de BARA: - O sonho da minha mãe sempre foi ver os dois formados. Processa-se, nos discursos dos jovens, a afirmação que o diploma é seu desejo e, ao mesmo tempo, remete aos desejos de seus outros significativos, no caso, de sua família.

Possuir o diploma faz parte da história do coletivo de jovens entrevistados. BONO: Porque ele é engenheiro, então, eu tinha que fazer Engenharia. Reproduzem, portanto, no paradigma da qualificação para o trabalho, a ideologia do diploma como salvaguarda do futuro, assim como seus pais acreditam.

Por outro lado, muitos alunos vêm de um coletivo, de uma geração de pais que, em sua maioria, não teve acesso ao sistema de ensino e cujas possibilidades de estudo foram limitadas ou até negadas. BIA: - Por ela não ter feito a faculdade, sempre quando ela vem para cá, ela pede para vir aqui, para ver a faculdade, ela acha muito lindo estudar. O sonho do diploma é estabelecido e mantido pelas relações que o sujeito estabelece com outros significativos, como em outra entrevistada, ANA: - Eles estão felizes com o diploma... querem que eu continue a estudar. Em sua história de escolhas, os jovens escolhem diplomas, assim como os pais, colegas ou professores, que influenciam a constituição de carreiras.

O diploma tem um sentido múltiplo, como condição de status social, de mobilidade e de melhores possibilidades de futuro e carreira, o que é evidenciado nos discursos: BARA: -...Eles querem que eu me dedique... Porque eles quiseram estudar, e, pelo fato de não terem conseguido, eles querem dar isso para gente agora, né? Eles não querem que eu pare de estudar nunca; depois, já vou continuar a fazer uma especialização, quem sabe outra faculdade.

Continuam se qualificando para entrar cada vez mais tardiamente no mercado de trabalho, como corroboram vários autores (Antunes, 2006; Aued, 2000; Pochmann, 1998, 2007; Fonseca \& Azevedo, 2007). Contraditoriamente, é o diploma que permite ao sujeito progredir em suas outras escolhas e possibilidades de carreira. Em um contexto competitivo, a lógica é que, quanto mais diplomado, melhor remunerado (Antunes, 2006).

Ter um diploma que se enquadre em áreas técnicas, que garanta condições materiais de sobrevivência e dinheiro é importante, como nos informa BONO: - Eu sempre coloquei na minha vida, e sempre tive isso dentro de casa que esse tipo... que essas áreas não iam me fornecer um futuro consistente. Os interesses dos formandos sobre a carreira são influenciados pela possibilidade de independência. BONO: - Mas trabalho, mesmo, eu acho que é ganhar dinheiro, ter uma vida estável e... essa coisa mais clássica, mesmo. 
Os diplomas que têm sentido para os pais movem-se no interior do discurso, do sentido produzido pelo outro, para o sentido pessoal: BONO: - O que eu quero hoje é o que meus pais sempre quiseram para mim. O discurso dos pais se revela no discurso dos filhos, conforme Fernandes (2006).

O final do curso impõe uma nova escolha de trabalho, com maior complexidade, a qual se relaciona com uma carreira capaz de fornecer um futuro consistente. Tornarse diplomado na universidade é mais importante e tem mais valor do que um trabalho que esteja relacionado diretamente com seus interesses ou aptidões.

\section{O medo do mercado de trabalho e as estratégias de enfrentamento}

O significado ideológico do mercado remete a algo situado fora de si mesmo que o ameaça e constrange e que se repete nos discursos. BIA: - Não, eu não me sinto preparada... O jovem encontra-se face a face com leis que regem a inserção profissional, as leis da oferta e da procura e os lugares sociais onde só os mais qualificados podem adentrar.

A expressão mercado de trabalho traz em si múltiplos significados, como estar preparado, construir conceitos ou ter experiência, como no exemplo de BIA: - Eu acho que a universidade, ela te ajuda a construir certos conceitos, uma visão muito geral, muitas vezes, né?... Mas não me sinto preparada... assim... com experiência para o mercado de trabalho. A contradição vivenciada pelos jovens é como se preparar para o desconhecido.

O discurso sobre o mercado de trabalho remete o jovem a um contexto de signos indecifráveis e impossíveis de serem conhecidos, como afirma BARA: - A faculdade, eu acho que em determinado curso, como é o meu caso, que a gente não tem muito contato realmente com o mercado de trabalho. Vivenciam, nos processos de recrutamento e seleção, as inseguranças futuras para se inserirem em suas áreas de trabalho, e começam a observar as possibilidades de carreira.

A pessoa que escolhe uma carreira deve, nesse momento de transição de vida, estar preparada ou mostrar-se apta: BIA: - Eu acho que a universidade ainda não tá preparando para o mercado de trabalho, ela tá só te dando alguns instrumentos, né? A expectativa dos formandos é de terem condições de se instrumentalizar não para um saber profissional, mas para o que o mercado de trabalho lhes solicita.

O medo do mercado se configura na necessidade de serem produtivos para a sociedade e para si mesmos: BIA: - Mas porque você já tem que escolher uma profissão, né, e daí... e essa profissão dá muito medo. Você cai ali... e vai fazendo... assim um monte de coisas. E o que eu vou fazer... O que eu vou fazer... Eu acabo caindo... assim na mesma situação do segundo grau, no mesmo, muitas vezes. Você sai de lá e daí... tá cheio de informação... Mas, e agora... né, e o mercado? A palavra medo marca a sua insegurança em relação ao mercado de trabalho, sua vivência de significativa ansiedade. Em sua fala, cair se refere a ser malsucedido, explicita a emoção característica desse momento, o medo, conforme corrobora Aued (2000). Os formandos se percebem imersos em condições que (des)fazem opções e possíveis caminhos de escolha, e o medo se revela no ato de cair.

As escolhas estão fortemente articuladas com a realidade de mercado de trabalho à qual se 
Para realizar

a escolha,

o formando

deve possuir

conhecimento

acerca de si

mesmo, de

suas aptidões,

gostos, interesses,

habilidades, valores,

competências

e sentimentos

em relação

ao trabalho,

como atestam

grande parte dos

pesquisadores

que trabalha

na área da OP

(Sarriera et al.,

2004; Soares \&

Lisboa, 2000;

Ferreti, 2004). vincula a carreira futura. ANA: - Eu fiz tantos estágios... Sabendo que tinha um mundo aí para eu conhecer, né? O formando prioriza a informação profissional em um percurso de estágios dentro da universidade, o que Ihe permite a transformação de sua carreira futura.

Contraditoriamente, ao trabalhar, tecem-se novas possibilidades de o jovem construir uma perspectiva de carreira. ANA: - Então eu comecei a me relacionar com as pessoas do departamento, com professores e funcionários, e isso foi me abrindo as portas assim. O formando participa como coautor de sua carreira a partir das relações assentadas sobre uma expectativa de futuro. ANA: $-E$ isso foi fundamental, eu vejo, foi fundamental para saber o que que eu quero fazer de agora em diante e o que eu não quero, porque, se eu não tivesse estágio como trabalho em movimentos sociais, eu não saberia que eu não quero... Assim, a realização de estágios contribui para combater a insegurança presente e para que o sujeito se perceba como coautor de sua realidade.

Suas condições se transformam e ele projetase no futuro, imagina-se como trabalhador e enfrenta o medo de se inserir nesse mercado. BONO: -... Quero ser engenheiro, e quero, eu vou ganhar dinheiro e ter minha vida, e vou comprar meu carro, minha casa e... meu cachorrinho e minha namo... minha mulher. Pronto! Os diferentes discursos nos revelam a importância das escolhas profissionais para a carreira futura dos formandos, que se constituem sobre um complexo de possibilidades contextuais e trajetórias vivenciadas durante o período de formação.

\section{Considerações Finais}

Os discursos nos revelam os sentidos da escolha profissional que se abrem para as relações entre o aluno e a universidade, e o percurso universitário e as inserções em estágios são aspectos essenciais no direcionamento da futura carreira dos jovens.

O processo de direcionamento da carreira está presente em sentidos pessoais e particulares da escolha inicial do curso superior, e a valorização da futura carreira se desloca através de diferentes referenciais, das vivências no contexto universitário e familiar, e, daquilo que dizem para os formandos sobre a profissão, passa-se para um discurso do sujeito que se apropria e ressignifica suas decisões. Na universidade, a dimensão da formação profissional configura-se em um projeto; conforme Dias e Soares, "em quase todas as circunstâncias vividas, precisamos de um projeto... uma antecipação da ação ou uma projeção de si no futuro" (2009, p. 83). Esse projeto de futuro profissional pode se concretizar a partir de estratégias de enfrentamento do medo do mercado de trabalho.

Na relação entre a subjetividade e a objetividade do mercado, a escolha profissional e as perspectivas de carreira se alteram e oscilam conforme o próprio mercado; assim, o jovem se apresenta muitas vezes escolhendo sem saber, conforme Bock (1995). Para realizar a escolha, o formando deve possuir conhecimento acerca de si mesmo, de suas aptidões, gostos, interesses, habilidades, valores, competências e sentimentos em relação ao trabalho, como atestam grande parte dos pesquisadores que trabalha na área da OP (Sarriera et al., 2004; Soares \& Lisboa, 2000; Ferreti, 2004). Em sua maioria, os vestibulandos não dispõem de informações suficientes para tecer escolhas nessa fase da vida, nem sobre os seus cursos superiores nem sobre seus interesses profissionais.

Na perspectiva da Psicologia social, a carreira envolve a representação pessoal de um futuro tecido sobre escolhas presentes que são sempre condicionadas a um passado historicamente construído. Consideramos que 
as escolhas de carreiras podem ser alteradas por condições históricas sociais objetivas ou subjetivas relacionadas com percepções do mercado de trabalho veiculadas em determinado meio social onde os períodos de transição são particularmente afetados.

Apresentaram-se-nos alunos que consideram o diploma mais importante que o trabalho, ou que buscam somente o retorno financeiro da atividade assente na lógica do capitalismo, evidenciado na fala de Bono -...Eu quero só é um emprego, mesmo. Antunes (2006) afirma que o trabalho encontra-se desviado perversamente na forma de emprego. O discurso dos formandos combina com uma preocupação entre o que se sonha fazer e a possibilidade de fazer, para que se possa vir a ser. Os jovens selecionam cursos nos quais o diploma é em si talvez o fator mais importante, porque, como nos informa BONO, ...o diploma serve para fornecer um futuro consistente. A utilidade da profissão por vezes se resume ao que é ditado socialmente, conforme Ferreti (2004), em algo que permita o ingresso mais fácil ao mercado de trabalho, com possibilidades de autonomia e de independência financeira.

A expressão mercado de trabalho revela uma ideologia que ameaça o cumprimento do futuro (Pochmann 1998, 2007) e que instala um constante estado de alerta, ansiedade e insegurança. Parte do orgulho inicial por ter adentrado a universidade vai se desvanecendo sob a ameaça do mercado de trabalho que, ainda na transição, é desconhecido pela maioria dos jovens.

As estratégias de enfrentamento do mercado são formas que qualificação extracurricular, com mais cursos e estágios, nos quais os jovens buscam se diferenciar dos demais, conforme assinalam Vieira e Coimbra (2006). Ao mesmo tempo, suas estratégias refletem ações no sentido de frequentar estágios para saber o que é o trabalho, conforme Dias e Soares: "Por meio do projeto, constrói-se um futuro desejado, e seu caráter parcialmente determinado faz com que ele não seja totalmente realizado e esteja sempre passível de modificações" (2009, p. 85). Os ensaios singulares são capazes de servir de sustentação para superar os obstáculos da transição como experiências de exercício profissional.

As escolhas direcionam a carreira, e se, no começo vivenciaram a insegurança e o desconhecimento sobre o curso, no final da graduação, revivem tais sentimentos quanto à profissão escolhida. ANA: - É isso, tem que trabalhar em qualquer coisa para sobreviver. Entre dúvidas, inseguranças e indecisões, a escolha da inserção profissional desenha uma direção específica na transição em que optar por qualquer curso revela a precariedade de informação existente também no momento do ingresso.

Os formandos vivenciam fases transitórias de escolhas e vão conformando novos objetivos e interesses; assim, os contextos universitários revelam uma grande possibilidade de inovar na área de orientação profissional, auxiliando os jovens na tomada de decisões da carreira. No período de transição, diversos autores salientam a necessidade de apoio e de orientação pela fragilidade do momento (Teixeira \& Gomes, 2004). A transição é um período que afeta a subjetividade dos formandos, e a escolha profissional tem relação com o direcionamento da carreira (Dutra, 2002) de universitários, como nesta fala de ANA: - Se eu não tivesse definido estas relações logo no começo, aí talvez eu chegasse até a sétima fase sem fazer estágio. Assim, o interesse pela profissão e uma trajetória acadêmica voltada para a carreira se iniciam ainda no contexto universitário, conforme Sarriera et al. (2004), quando o aluno começa a pensar sobre o seu futuro profissional.

Os contextos de transição revelam um momento em que é importante trazer informações sobre a inserção profissional, representam um desafio e uma oportunidade para o 
trabalho do psicólogo e, para os jovens, podem representar o auxílio necessário para a superação de ansiedades quanto ao futuro profissional. Contraditoriamente, a transição é uma fase na qual os jovens podem realizar seus desejos, aquilo que sonharam, escolhendo entre as possibilidades de trabalho aquelas que lhes permitam ser autônomos em sua alteridade. Pela complexidade da área, urgem novas abordagens e novos campos de atuação para o orientador profissional, que não pode perder de vista o objetivo de trabalhar para a Saúde Mental do sujeito em suas relações de trabalho. 


\section{Maria Sara de Lima Dias}

Doutorado em Psicologia pela Universidade Federal de Santa Catarina. Mestre em Psicologia da infância e Adolescência e graduação em Psicologia pela Universidade Federal do Paraná. Professora da Universidade Tuiuti do Paraná , PR - Brasil.

E-mail: msaradldias@gmail.com/maria.dias@utp.br

\section{Dulce Helena Penna Soares}

Psicóloga e Pós Doutora pela Universidade Federal do Rio Grande do Sul. Doutora em Piscologia pela

Universidade de Starasbourg, França. Professora Associada III da Universidade Federal de Santa Catarina, Santa

Catarina - SC - Brasil.

E-mail: dulce@cfh.ufsc.br / dulcepenna@terra.com.br

\section{Endereço para envio de correspondência:}

Rua Sydnei A Rangel Santos, 238, Bairro Santo Inácio-Paraná- PR-Brasil, CEP. 82.010-330

Recebido 19/1/2010, 1a Reformulação 28/10/2011, Aprovado 10/1/2012. 
Antunes, R. (2006). Os sentidos do trabalho. São Paulo: Boitempo Editorial.

Aued, B. W. (Org.). (2000). Educação para o (des)emprego (ou quando estar liberto da necessidade do emprego é um tormento). Petrópolis, RJ: Vozes.

Bardagi, M., Lassance, M. C. P., Paradiso, Â. C., \& Menezes, I. A. de. (2006). Career choice and insertion in labor market: Perceptions from college seniors. Psicologia Escolar e Educacional, 10(1), 69-82.

Borges-Andrade, J. E., \& Bastos, A. V. B. (Orgs.). (2004). Psicologia, organizações e trabalho no Brasil. Porto Alegre: Artmed.

Bock, S. D. (1995). Concepções de indivíduo e sociedade e as teorias em orientação profissional. In C. M. M. Amaral, L. Q. de Andrade, W. M. J. Aguiar \& A. M. B. Bock (Orgs.), A escolha profissional em questão (2a ed. pp. 61-70). São Paulo: Casa do Psicólogo.

Censo da Educação Superior. (2009). Recuperado em 20 de agosto de http://sistemascensosuperior.inep.gov.br/ censosuperior_2011/

Chanlat, J. (1996). (Coord.), O indivíduo na organização: dimensões esquecidas. São Paulo: Atlas.

Dias, M. S. d. L., \& Soares, D. (2009). Planejamento de carreira: uma orientação para estudantes universitários. São Paulo: Vetor.

Dutra, J. S. (2002). Gestão de carreiras. In M. T. L. Fleury. As pessoas nas organizações. São Paulo: Gente.

Fernandes, D. C. (2006). Mitos familiares e escolha profissional: uma visão sistêmica. Psic, 7(1), 99-100.

Ferreti, C. J. (1988a). Uma nova proposta de orientação profissional. São Paulo: Cortez.

Ferreti, C. J. (1988b). Opção: trabalho: trajetórias ocupacionais de trabalhadores das classes subalternas. São Paulo: Cortez.

Ferreti, C. J. (2004). Considerações sobre a apropriação das noções de qualificação profissional pelos estudos a respeito das relações entre trabalho e educação. Educação \& Sociedade, 25(87), 401-422.

Fonseca, M. A., \& Azevedo, J. (2007). Imprevisíveis itinerários de transição escola-trabalho: a expressão de uma outra sociedade. Vila Nova de Gaia, Portugal: Fundação Manuel Leitão.

Jonhson, M. C. (2000). Projeto de vida e trabalho: a orientação profissional na perspectiva de orientadores. Dissertação de Mestrado, Faculdade de Educação, Universidade Estadual de Campinas, São Paulo

Pochmann, M. (1998). A inserção ocupacional e o emprego dos jovens. São Paulo: Associação Brasileira de Estudos do Trabalho.
Pochmann, M. (2007). A batalha pelo primeiro emprego: a situação atual e as perspectivas do jovem no mercado de trabalho brasileiro (2a ed). São Paulo: Publischer.

Sarriera, J. C., Rocha, K. B., \& Pizzinato, A. (Orgs.), (2004). Os desafios do mundo do trabalho. Porto Alegre: Edipucrs.

Savickas, M. L. (2004). Um modelo de avaliação. In L. M. Leitão, (Coord.), Avaliação psicológica em orientação escolar e profissional. Coimbra: Quarteto.

Savickas, M. L. (2005). The theory and practice of career construction. In R. W. Lent \& S. D. Brown (Eds.), Career development and counseling: Putting theory and research to work (pp. 42-70). Hoboken, NJ: Wiley.

Soares, D. H. P., \& Lisboa, M. L. (2000). Orientação profissional em ação: formação e prática de orientadores. São Paulo: Summus.

Soares, D. H. P. (2002). A escolha profissional do jovem ao adulto. São Paulo: Summus.

Sparta, M. (2003). O desenvolvimento da orientação profissional no Brasil. Revista Brasileira de Orientação Profissional, 4(1-2), 1-11.

Super, D. E. (1957). The psychology of careers. New York: Harper \& Row.

Super, D. E. (1983). Assessment in career guidance: Toward truly developmental counseling. Personnel and Guidance Journal, 61, 555-562.

Teixeira, M. A. P., \& Gomes, W. B. (2004). Estou me formando... e agora?: Reflexões e perspectivas de jovens formandos universitários. Revista Brasileira de Orientação Profissional, 5(1), 47-62.

Vieira, D., \& Coimbra, J. L. (2006). Sucesso na transição escola-trabalho: a percepção de finalistas do ensino superior português. Revista Brasileira de Orientação Profissional, 7(1), $1-10$.

Vygotsky, L. S. (1991a). La conciencia como problema de la psicologia del comportamiento. In L. S. Vygotsky. Obras Escogidas I: Problemas teóricos y metodológicos de la psicología (pp. 39-60). Madri: Visor Distribuiciones.

Vygotsky, L. S. (1991b). La psique, la conciencia, el inconsciente. In L. S. Vygotsky. Obras Escogidas I: Problemas teóricos y metodológicos de la psicología (pp. 95-110). Madri: Visor Distribuiciones.

Vygotsky, L. S. (2000). Pensamento e linguagem (2a ed.). São Paulo: Martins Fontes. Antunes, R. (2006). Os sentidos do trabalho. São Paulo: Boitempo Editorial. 